\title{
Thermodynamic Analysis of Phenol Acylation with Acetic Acid
}

\author{
E. Vitor Sobrinho ${ }^{a}$, D. Cardoso $^{a}{ }^{*}$, and E.F. Souza-Aguiar ${ }^{b}$ \\ ${ }^{a}$ Departamento de Engenharia Química, Universidade Federal de S. Carlos, \\ 13.565-905 S.Carlos - SP, Brazil; e-mail : dilson@power.ufscar.br \\ ${ }^{b}$ Cenpes-Petrobras, Ilha do Fundão, 21.949-900 Rio de Janeiro - RJ, Brazil; \\ ${ }^{b}$ Escola de Química, Universidade Federal do Rio Janeiro - RJ, Brazil
}

Received: March 4, 1997

\begin{abstract}
Hidroxiacetofenonas, especialmente o isômero para, são importante compostos da industria farmacêutica. Elas podem ser obtidas por acilação do fenol, mas as propriedades termodinâmicas dessa reação não estão disponíveis. A estimativa das propriedades desta reação, usando o método de Benson, indica que a formação das hidroxiacetofenonas é favorável a temperaturas entre $300 \mathrm{~K}$ e $800 \mathrm{~K}$. Temperaturas superiores favorecem a formação do acetato de fenila. Neste intervalo de temperatura, a meta-hidroxiacetofenona é mais estável que os isômeros orto e para.
\end{abstract}

Hydroxyacetophenones, especially the para-isomer, are important compounds in the pharmaceutical industry. They can be obtained through acylation of phenol but no data about the thermodynamic properties of this reaction are available. The estimation of the properties of this reaction, using the Benson method, shows that the formation of hydroxyacetophenones is favorable at temperatures between $300 \mathrm{~K}$ and $800 \mathrm{~K}$. Higher temperatures favor the formation of phenyl acetate. In this temperature range, meta-hydroxyacetophenone is more stable than the other isomers.

Keywords: thermodynamic, phenol acylation, hydroxyacetophenone

\section{Introduction}

Acylation reactions are largely employed in the fine chemical industry, producing a variety of synthetic fragrances and pharmaceuticals. The principal route to obtain acylaromatics, for example, is the acylation of aromatics, which is generally carried out using Brönsted or Lewis acid catalysts $^{1,2}$.

Hydroxyacetophenones, especially the ortho and paraisomers, which are required in the fabrication of pharmaceutical products ${ }^{4,5}$ stand out among the aromatic products. These compounds can be obtained by direct C-acylation of phenol with acetic acid or rearrangement of phenyl acetate (Fries Reaction, Eq. 2, Fig. 1). Obviously, the first route is more interesting since it employs more readily available and less expensive raw materials but, due to the greater electron density of the oxygen atom of the phenol molecule, the formation of the hydroxyacetophenones occurs essentially through O-acylation and ester formation (Eq. 1). Several authors have studied this route in liquid phase ${ }^{3}$ or gas phase ${ }^{4,5,6}$. In both case the primary product is the phenyl acetate and the hydroxyacetophenones are secondary products. Additionally, for kinetic reasons, the phenyl acetate formation is much faster than its isomerization ${ }^{7}$. However, to the best of our knowledge, no thermodynamic study of this reaction has been carried out, aiming to evaluate the appropriate conditions for the optimal formation of the desired isomers.

Hence, the goal of this work was to estimate thermodynamic parameters, like enthalpy, Gibbs energy of formation and the equilibrium constant of this reaction, as well as the hydroxyacetophenone isomer's distribution at thermodynamic equilibrium. Furthermore, the aim of this work is also to emphasize the importance of the use Benson's method, which is recommended for the estimation of thermodynamic parameters for aromatic isomers.

\section{Calculations}

The main difficulty in estimating the thermodynamic properties of reactions 1 and 2 is to evaluate the free Gibbs energy of formation of the hydroxyacetophenone (HAP) 
<smiles>Oc1ccccc1</smiles>

Phenol
$+\mathrm{CH}_{3} \mathrm{COOH}$

Acetic Acid

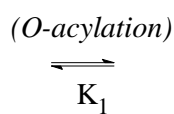

$\mathrm{K}_{1}$

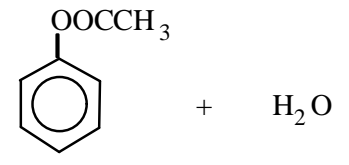

Phenylacetate + Water

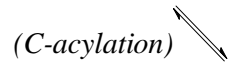

Figure 1. Phenol acylation and Fries isomerization.

isomers. Ried et al. ${ }^{8}$ mention different ways to estimate the thermodynamic properties of organic compounds, like the methods of Yoneda, Joback, Thin, Cardozo and Benson. He indicate that the last one offered the best estimated values for the case of organic isomers, giving errors lower than $1 \%$ and, therefore, the Benson method will be used in this work.

Benson's method used for the estimation of standard enthalpy of formation $\left(\Delta \mathrm{H}_{\mathrm{f}}{ }^{\circ} 298\right)$, absolute entropy $\left(\mathrm{S}^{\circ}{ }_{298}\right)$ and ideal-gas heat capacity $\left(\mathrm{Cp}^{\circ}\right)$, is described in his comprehensive review ${ }^{9}$. It considers that molecules are formed by groups of atoms. Each group is marked for the key atom with valence greater than unity, followed by a notation specifying other atoms bonded to it. The phenol molecule, for instance, has six groups of atoms: (a) one group formed by the phenol function, symbolized by $\mathrm{O}-(\mathrm{H})\left(\mathrm{C}_{\mathrm{B}}\right)$ and $(\mathrm{b})$ five groups formed by a hydrogen atom bonded to an aromatic carbon $\mathrm{C}_{\mathrm{B}}-(\mathrm{H})$ where $\mathrm{C}_{\mathrm{B}}$ represents an aromatic carbon.

Equations 3, 4 and 5 show the expressions for the estimation of the enthalpy of formation, heat capacity and entropy of the compounds in reactions 1 and 2, respectively. They are obtained by summing the contributions of each $i$-group $\left(\Delta \mathrm{H}_{\mathrm{i}}, \mathrm{Cp}^{\circ}(\mathrm{T})\right.$ and $\left.\mathrm{S}_{\mathrm{i}}{ }_{\mathrm{i}}\right)$, which are tabulated by Ried et al. ${ }^{8}$ and Benson et al. ${ }^{9}$, taking into account the frequency of appearance $n_{i}$ of each group in the molecule:

$$
\begin{aligned}
& \Delta \mathrm{H}_{\mathrm{f}}{ }^{\circ} 298=\sum \mathrm{n}_{\mathrm{i}} \Delta \mathrm{H}_{\mathrm{i}} \\
& \Delta \mathrm{H}_{\mathrm{f}}{ }^{\circ} 298=\Sigma \text { ni } \Delta \mathrm{Hi} \\
& \mathrm{S}^{\circ} 298=\Sigma \mathrm{ni} \mathrm{S}^{\circ} \mathrm{i}-\mathrm{R} \ln (\sigma)-\mathrm{R} \ln (\eta)
\end{aligned}
$$

The Benson method requires the correction of the sum of the entropies (Eq. 5) using the symmetry number $(\sigma)$ and the number of possible optical isomers $(\eta)$. Ried et al. ${ }^{8}$ and Benson et al. $^{9}$ present several suggestions defining the symmetry number $(\sigma)$ of different molecules; nevertheless, we were not able to find any tabled value for $\sigma$ corresponding to hydroxyacetophenones. According to these authors, the symmetry number of the molecule can be obtained by the product of the internal symmetry number $\left(\sigma_{\text {int }}\right)$ and the external symmetry number $\left(\sigma_{\text {ext }}\right)$ :

$$
\sigma=\sigma_{\text {int }} . \sigma_{\text {ext }}
$$

The $\sigma_{\text {int }}$ parameter represents the number of symmetry elements of each group and $\sigma_{\text {ext }}$ represents the number of symmetry elements of the whole molecule. Accordingly, the ortho and meta-hydroxyacetophenone isomers have $\sigma_{\text {int }}$ $=3$ (since only the methyl group has symmetry elements) and $\sigma_{e x t}=1$, which is the plane defined by the aromatic ring. The para-hydroxyacetophenone has the same $\sigma_{\text {int }}$ value and $\sigma_{\text {ext }}=2$ since, besides the plan defined by the aromatic ring, it has a symmetry axis defined by the para-positions in the aromatic ring. Therefore, $\sigma=3$ for the ortho and meta isomers and $\sigma=6$ in the case of the para-HAP. There are no optical isomers among the HAP, and consequently this correction in Eq. 5 is not necessary.

The Benson method ${ }^{9}$ also demands fixed corrections for the following properties of ortho-isomers of aromatic compounds:

$$
\begin{aligned}
& \Delta \mathrm{H}_{\mathrm{f}}{ }^{\circ} 298=\Delta \mathrm{H}_{\mathrm{f}}{ }^{\circ}-0.57 \\
& \mathrm{~S}_{298}^{\circ}=\mathrm{S}^{\circ}-1.61
\end{aligned}
$$




$$
\begin{aligned}
& \mathrm{Cp}_{300}=\mathrm{Cp}^{\circ}+1.12 \\
& \mathrm{Cp}_{400}=\mathrm{Cp}^{\circ}+1.35 \\
& \mathrm{Cp}_{500}=\mathrm{Cp}^{\circ}+1.30 \\
& \mathrm{Cp}_{600}=\mathrm{Cp}^{\circ}+1.17 \\
& \mathrm{Cp}_{800}=\mathrm{Cp}^{\circ}+0.88
\end{aligned}
$$

Equation 7 shows how the entropy of formation of each compound $\left(\mathrm{S}_{\mathrm{f}}{ }^{0}{ }^{2} 98\right)$ can be calculated from its chemical elements

$$
\Delta \mathrm{S}_{\mathrm{f}}{ }^{\mathrm{o}} 298=\mathrm{S}^{\circ} 298-\Sigma \mathrm{Se}_{\mathrm{e}}{ }^{\circ} 298^{9}
$$

where:

$$
\begin{array}{r}
\mathrm{S}_{\mathrm{e}}{ }^{\mathrm{o}}{ }_{298}\left(\mathrm{H}_{2}\right)=31.21 \mathrm{cal} / \mathrm{mol} \mathrm{K} \\
\mathrm{S}_{\mathrm{e}}{ }^{\mathrm{o}} 298(\mathrm{C})=1.361 \mathrm{cal} / \mathrm{mol} \mathrm{K} \\
\mathrm{S}_{\mathrm{e}}{ }^{\mathrm{o}}{ }_{298}\left(\mathrm{O}_{2}\right)=49.00 \mathrm{cal} / \mathrm{mol} \mathrm{K}
\end{array}
$$

Finally, we can estimate the thermodynamic properties and the chemical equilibrium constant $(\mathrm{K})$ of the reactions at different temperatures as follows:

$$
\begin{aligned}
& \mathrm{C}_{\mathrm{p} \mathrm{m}}^{\circ}=\frac{\mathrm{C}_{\mathrm{p}}^{\circ}(\mathrm{T})+\mathrm{C}_{\mathrm{p} 298}^{\circ}}{2} \\
& \Delta \mathrm{H}_{\mathrm{f}}^{\circ}(\mathrm{T})=\Delta \mathrm{H}_{\mathrm{f}}^{\mathrm{o}} 298+\mathrm{Cp}^{\circ} \mathrm{m}(\mathrm{T}-298) \\
& \Delta \mathrm{S}_{\mathrm{f}}{ }^{\circ}(\mathrm{T})=\Delta \mathrm{S}_{\mathrm{f}}{ }^{\circ} 298+\mathrm{Cp}_{\mathrm{m}}^{\mathrm{o}} \cdot \ln (\mathrm{T} / 298) \\
& \Delta \mathrm{G}_{\mathrm{f}}^{\mathrm{o}}(\mathrm{T})=\Delta \mathrm{H}_{\mathrm{f}}{ }^{\circ}(\mathrm{T})-\mathrm{T} \cdot \Delta \mathrm{S}_{\mathrm{f}}{ }^{\mathrm{o}}(\mathrm{T}) \\
& \mathrm{K}(\mathrm{T})=\exp \left[\frac{-\Delta \mathrm{G}_{\mathrm{f}}^{\circ}(\mathrm{T})}{\mathrm{RT}}\right]
\end{aligned}
$$

By knowing the equilibrium constant $\left(\mathrm{K}_{1}\right)$ of the formation of phenyl acetate (Eq. 1) and of hydroxyacetophenone isomers $\left(\mathrm{K}_{2 \mathrm{o}}, \mathrm{K}_{2 \mathrm{~m}}\right.$ e $\mathrm{K}_{2 \mathrm{p}}$, Eq. 2), other parameters of both reactions at a given temperature can be calculated: the phenol and acetic acid molar consumption (x) at the chemical equilibrium, the molar conversion to phenyl acetate $(\mathrm{x}-\mathrm{y})$ or hydroxyacetophenone $(\mathrm{y})$ and the molar fraction of hydroxyacetophenone isomers $\left(f_{o}, f_{m}\right.$ e $\left.f_{p}\right)$. The values of these parameters can be achieved solving the system formed by Eqs. 15, 16 and 17, supposing that initially the reactants are in a specific molar proportion (equimolar and unitary, for instance).

$$
\text { Phenol + Acetic Acid } \stackrel{K_{1}}{\leftrightarrow} \text { Phenyl Acetate + Water (1) }
$$$$
(1-\mathrm{x}) \quad(1-\mathrm{x}) \quad(\mathrm{x}-\mathrm{y}) \quad \mathrm{x}
$$

Phenyl Acetate $\stackrel{K_{2 i}}{\leftrightarrow}$ o, m, p-Hydroxyacetophenones(2)

$$
(x-y)
$$

The equilibrium constant of reactions 13 and 14 yields, respectively:

$$
\begin{aligned}
& K_{1}=\frac{x(x-y)}{(1-x)^{2}} \\
& K_{2 i}=\frac{f_{i} y}{x-y} \\
& \sum_{i=1}^{3} f_{i}=1
\end{aligned}
$$

referring $\mathrm{f}_{i}$ to the molar fraction of $\mathrm{o}, \mathrm{m}$ or $\mathrm{p}$ - hydroxyacetophenones isomers.

Solving the system formed by the Eqs. 15, 16, and 17 we obtain the molar consumption of reactants (18), the conversion (19) and the selectivity to hydroxyacetophenones (20):

$$
\begin{aligned}
& x=\frac{\sqrt{2} K_{1}\left(K_{1}+a\right)}{a} \\
& y=\frac{x \sum_{i=1}^{3} K_{2 i}}{1+\sum_{i=1}^{3} K_{2 i}}
\end{aligned}
$$

where

$$
\mathbf{a}=1-\mathbf{K}_{\mathbf{1}}-\frac{\sum_{\mathbf{i}=1}^{3} \mathbf{K}_{2 \mathbf{i}}}{1+\sum_{\mathbf{i}=1}^{3} \mathbf{K}_{2 \mathbf{i}}}
$$

and

$$
\mathbf{S}_{\mathrm{HAF}}=\frac{\mathbf{y}}{\mathbf{x}}
$$

Once the values of $\mathrm{x}$ and $\mathrm{y}$ have been established for a certain temperature, the molar fractions of the HAF isomers $\left(\mathrm{f}_{\mathrm{i}}\right)$ can be determined from Eq. 16.

\section{Results and Discussions}

Thermodynamic properties of the phenol esterification reaction

Table 1 shows the chemical groups present in the phenyl acetate (PA) and hydroxyacetophenone (HAP), the number of times that each group appears in these molecules, and the thermodynamic properties of each one. The value of the group contributions for the calculation of its thermodynamic properties was furnished by Ried $e t a l{ }^{8}$ and Benson et al. ${ }^{9}$.

Table 2 shows the results for the thermodynamic properties of formation of phenyl acetate at various tempera- 
Table 1. Contribution of the groups for the thermodynamic properties of PA and HAP.

\begin{tabular}{|c|c|c|c|c|c|c|c|c|}
\hline \multirow[t]{2}{*}{ Group } & \multirow[t]{2}{*}{$\mathrm{n}_{\mathrm{PA}}$} & \multirow[t]{2}{*}{$\mathrm{n}_{\mathrm{HAP}}$} & \multirow{2}{*}{$\begin{array}{c}\Delta \mathrm{H}_{\mathrm{i}} / \\
\mathrm{Kcal} / \mathrm{mol}\end{array}$} & \multirow{2}{*}{$\begin{array}{c}\mathrm{S}^{\circ}{ }_{\mathrm{i}} / \\
\mathrm{cal} / \mathrm{molK}\end{array}$} & \multicolumn{4}{|c|}{$\mathrm{Cp}_{\mathrm{i}}^{\circ} / \mathrm{cal} / \mathrm{mol} \mathrm{K}$} \\
\hline & & & & & $298 \mathrm{~K}$ & $400 \mathrm{~K}$ & $600 \mathrm{~K}$ & $800 \mathrm{~K}$ \\
\hline $\mathrm{C}_{\mathrm{B}^{-}}(\mathrm{H})$ & 5 & 4 & 3.30 & 11.53 & 3.24 & 4.44 & 6.30 & 7.64 \\
\hline $\mathrm{C}_{\mathrm{B}-}(\mathrm{O})$ & 1 & 1 & -1.80 & -10.12 & 3.90 & 5.30 & 6.60 & 6.90 \\
\hline $\mathrm{C}_{\mathrm{B}}-(\mathrm{CO})$ & 0 & 1 & 9.70 & 0 & 2.67 & 3.14 & 4.15 & 4.96 \\
\hline $\mathrm{C}-(\mathrm{CO})\left(\mathrm{H}_{3}\right)$ & 1 & 1 & -10.08 & 30.41 & 6.19 & 7.84 & 10.79 & 13.02 \\
\hline $\mathrm{CO}-\left(\mathrm{C}_{\mathrm{B}}\right)(\mathrm{C})$ & 0 & 1 & -37.60 & 0 & 5.68 & 6.92 & 8.37 & 9.40 \\
\hline $\mathrm{O}-\left(\mathrm{C}_{\mathrm{B}}\right)(\mathrm{H})$ & 0 & 1 & -37.60 & 29.10 & 4.30 & 4.50 & 5.20 & 6.00 \\
\hline $\mathrm{CO}-(\mathrm{O})(\mathrm{C})$ & 1 & 0 & -33.40 & 14.78 & 5.97 & 6.70 & 8.02 & 8.87 \\
\hline $\mathrm{O}-(\mathrm{Cb})(\mathrm{CO})$ & 1 & 0 & -32.52 & 0 & 2.06 & 2.71 & 3.42 & 3.88 \\
\hline
\end{tabular}

Table 2. Thermodynamic properties of PA formation.

\begin{tabular}{lcccc}
\hline $\mathrm{T} / \mathrm{K}$ & $\mathrm{Cp}^{\circ} / \mathrm{cal} / \mathrm{mol} \mathrm{K}$ & $\Delta \mathrm{H}_{\mathrm{f}}{ }^{\circ} / \mathrm{Kcal} / \mathrm{mol}$ & $\Delta \mathrm{S}_{\mathrm{f}}{ }^{\circ} / \mathrm{cal} / \mathrm{mol} \mathrm{K}$ & $\Delta \mathrm{G}_{\mathrm{f}}{ }^{\circ} / \mathrm{Kcal} / \mathrm{mol}$ \\
\hline 298 & 34.32 & -61.30 & -94.28 & -33.21 \\
400 & 44.75 & -57.27 & -82.64 & -24.21 \\
500 & 53.41 & -52.44 & -71.58 & -16.65 \\
600 & 60.33 & -47.01 & -61.16 & -10.31 \\
700 & 66.14 & -41.11 & -51.38 & -5.14 \\
800 & 70.37 & -35.02 & -42.59 & -0.95 \\
900 & 73.06 & -28.98 & -34.94 & 2.46 \\
1000 & 74.31 & -23.17 & -28.52 & 5.35 \\
\hline
\end{tabular}

tures, obtained by Benson group contribution method (Eqs. 3, 4 and 5) and Eqs. 8, 9, 10 and 11.

Similarly, Tables $3 \mathrm{a}$ and $\mathrm{b}$ indicate the thermodynamic properties of formation of the hydroxyacetophenones isomers at the same temperature interval, taking into account the symmetry number (Eq. 5) and the fixed corrections for the ortho-HAP isomer (Eqs. 6 a-g). The values of the free Gibbs energy of formation of the other compounds involved in the acylation reaction (phenol, acetic acid and water) were reproduced from Stull et al. ${ }^{10}$.

Table 4 presents free Gibbs energy of reaction $\left(\Delta \mathrm{G}_{\mathrm{r} 1}\right)$ of formation of phenyl acetate (Eqs. 1 and 13). The equilibrium constant $\left(\mathrm{K}_{1}\right)$ of this reaction indicates that (Fig. 2) the formation of phenyl acetate is more favorable at high temperatures reasonable values only at temperatures higher than $800 \mathrm{~K}$. Table 4 also displays the free Gibbs energy ( $\Delta \mathrm{G}_{\mathrm{ro}}, \Delta \mathrm{G}_{\mathrm{rm}}$ e $\Delta \mathrm{G}_{\mathrm{rp}}$ ) of the isomerization reaction of phenyl acetate to hydroxyacetophenones (Eqs. 2 and 14). The corresponding equilibrium constants $\left(\mathrm{K}_{2 \mathrm{o}}, \mathrm{K}_{2 \mathrm{~m}}\right.$ e $\left.\mathrm{K}_{2 \mathrm{p}}\right)$ of the Fries reaction (Fig. 2) indicate that the formation of these isomers, on the contrary, decrease continuously by increasing the temperature and the hydroxyacetophenones' formation reaction is less favorable at temperatures higher than $800 \mathrm{~K}$.

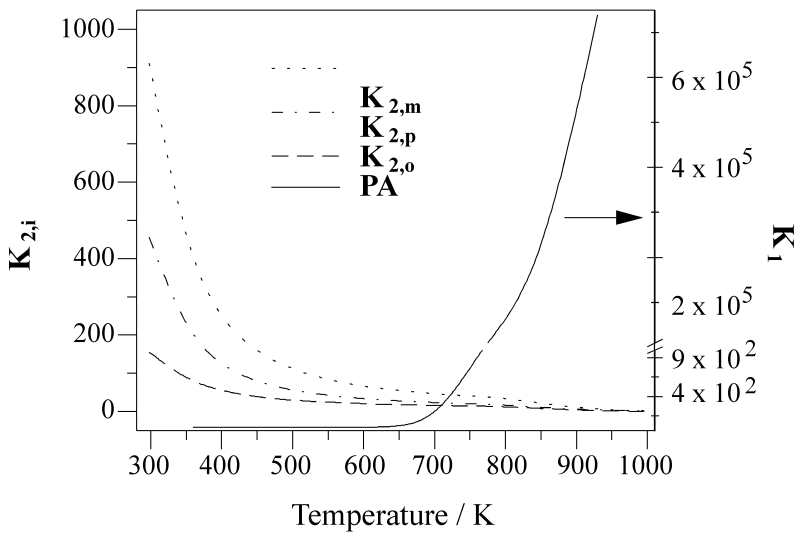

Figure 2. Equilibrium constants for phenyl acetate and hydroxyacetophenone formation.

\section{Reaction conversion and product distribution}

Figure 3 presents the estimated values of the phenol and acetic acid conversion ( $\mathrm{x}$ ), the molar conversion to phenyl acetate (x-y) and hydroxyacetophenone, HAP (y) as a function of the temperature. It shows that the reactant consumption is very small at temperatures below $400 \mathrm{~K}$, but it reaches almost $100 \%$ at temperatures higher than 800 $\mathrm{K}$. Among the products, the formation of hydroxyacetophe- 
nones is almost $100 \%$ selective up to $800 \mathrm{~K}$ (Fig. 3). At higher temperatures their formation decreases about $20 \%$, favoring phenyl acetate formation.

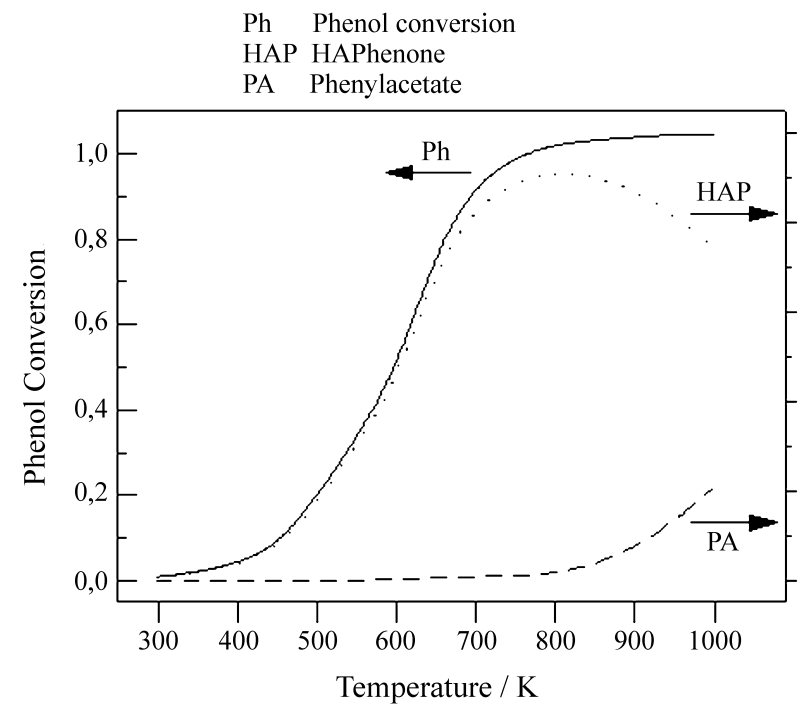

Figure 3. Conversion and acylation products of phenol with acetic acid.
The distribution of ortho, meta and para-hydroxyacetophenone isomers $\left(f_{o}, f_{m}\right.$ and $\left.f_{p}\right)$ as a function of the temperature is shown in Fig. 4. The results indicate that meta is the most and ortho the least stable of all isomers. It can be also observed that, as the temperature increases, there is a decrease in the fraction of meta and para isomers and a consequent increase in the ortho-isomer.

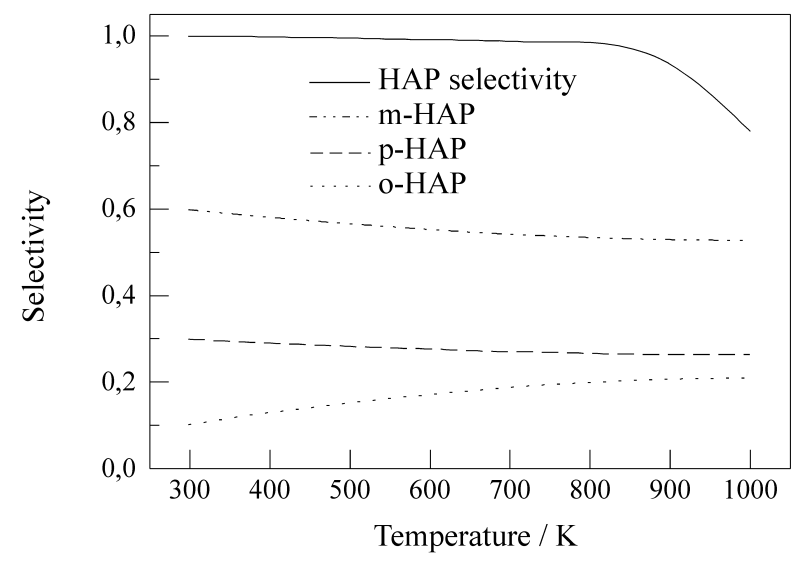

Figure 4. Selectivity for hydroxyacetophenone and isomer distribution at equilibrium.

Table 3a. Thermodynamic properties of ortho-HAP formation.

\begin{tabular}{lcccc}
\hline $\mathrm{T} / \mathrm{K}$ & $\mathrm{Cp}^{\circ} / \mathrm{cal} / \mathrm{mol} \mathrm{K}$ & $\Delta \mathrm{H}_{\mathrm{f}}{ }^{\circ} / \mathrm{Kcal} / \mathrm{mol}$ & $\Delta \mathrm{S}_{\mathrm{f}}{ }^{\circ} / \mathrm{cal} / \mathrm{mol} \mathrm{K}$ & $\Delta \mathrm{G}_{\mathrm{f}}{ }^{\circ} / \mathrm{Kcal} / \mathrm{mol}$ \\
\hline 298 & 36.82 & -63.91 & -93.02 & -36.19 \\
400 & 46.81 & -59.64 & -80.71 & -27.36 \\
500 & 54.93 & -54.64 & -69.28 & -20.00 \\
600 & 61.48 & -49.07 & -58.62 & -13.89 \\
700 & 67.19 & -43.00 & -48.61 & -8.98 \\
800 & 71.32 & -36.77 & -39.62 & -5.07 \\
900 & 73.97 & -30.56 & -31.79 & -1.95 \\
1000 & 75.27 & -24.57 & -25.17 & 0.60 \\
\hline
\end{tabular}

Table 3b. Thermodynamic properties of meta and para-HAP isomer formation.

\begin{tabular}{|c|c|c|c|c|c|c|}
\hline \multirow[b]{2}{*}{$\mathrm{T} / \mathrm{K}$} & \multicolumn{2}{|c|}{ meta and para } & \multicolumn{2}{|c|}{ meta } & \multicolumn{2}{|c|}{ para } \\
\hline & $\mathrm{Cp}^{\circ} / \mathrm{cal} / \mathrm{mol} \mathrm{K}$ & $\Delta \mathrm{H}_{\mathrm{f}}{ }^{\circ} / \mathrm{Kcal} / \mathrm{mol}$ & $\Delta \mathrm{S}_{\mathrm{f}^{\circ}} / \mathrm{cal} / \mathrm{mol} \mathrm{K}$ & $\Delta \mathrm{G}_{\mathrm{f}}^{\circ} / \mathrm{Kcal} / \mathrm{mol}$ & $\Delta \mathrm{S}_{\mathrm{f}}{ }^{\circ} / \mathrm{cal} / \mathrm{mol} \mathrm{K}$ & $\Delta \mathrm{G}_{\mathrm{f}}^{\circ} / \mathrm{Kcal} / \mathrm{mol}$ \\
\hline 298 & 35.70 & -64.48 & -91.41 & -37.24 & -92.79 & -36.83 \\
\hline 400 & 45.46 & -60.34 & -79.46 & -28.56 & -80.84 & -28.00 \\
\hline 500 & 53.63 & -55.46 & -68.30 & -21.31 & -69.68 & -20.62 \\
\hline 600 & 60.31 & -49.98 & -57.81 & -15.29 & -59.19 & -14.47 \\
\hline 700 & 66.08 & -44.03 & -47.95 & -10.46 & -49.33 & -9.49 \\
\hline 800 & 70.44 & -37.84 & -39.00 & -6.64 & -40.38 & -5.53 \\
\hline 900 & 73.38 & -31.65 & -31.13 & -3.63 & -32.51 & -2.39 \\
\hline 1000 & 75.07 & -25.60 & -24.36 & -1.24 & -25.74 & 0.14 \\
\hline
\end{tabular}


Table 4. The Gibbs energies for the O-acylation of phenol (Eq. 1) and the Fries isomerization (Eq. 2).

\begin{tabular}{lcccc}
\hline PA (Eq.1) & HAP (Eq. 2) & & \\
\hline $\mathrm{T} / \mathrm{K}$ & $\Delta \mathrm{G}_{\mathrm{r} 1} / \mathrm{Kcal} / \mathrm{mol}$ & $\Delta \mathrm{G}_{\mathrm{ro}} / \mathrm{Kcal} / \mathrm{mol}$ & $\Delta \mathrm{G}_{\mathrm{rm}} / \mathrm{Kcal} / \mathrm{mol}$ & $\Delta \mathrm{G}_{\mathrm{rp}} / \mathrm{Kcal} / \mathrm{mol}$ \\
\hline 298 & 10.04 & -2.99 & -4.04 & -3.62 \\
400 & 9.92 & -3.15 & -4.34 & -3.79 \\
500 & 8.16 & -3.35 & -4.66 & -3.97 \\
600 & 5.97 & -3.58 & -4.98 & -4.15 \\
700 & 0.46 & -3.84 & -5.32 & -4.35 \\
800 & -5.31 & -4.11 & -5.68 & -4.58 \\
900 & -13.06 & -1.95 & -3.63 & -2.39 \\
1000 & -22.27 & 0.60 & -1.24 & 0.14 \\
\hline
\end{tabular}

The higher stability of the meta-HAP isomer (about $60 \%$ of the isomers) is very similar to that presented by other disubstituted benzenic compounds, as in the case of the xylenes ${ }^{11}$. However, stability of the ortho isomer (between 10 and $20 \%$ of the isomers) is somewhat lower than that found among the xylenes but is comparable to that of the diethylbenzenes ${ }^{12}$. This indicates that the formation of the ortho-isomer of disubstituted benzenic compounds is influenced by the size but apparently not by the electronic properties of the substitutes present in the aromatic ring.

\section{Conclusions}

This work presents the necessary steps for the calculation of thermodynamic properties of hydroxyacetophenones, an important group of compounds employed in the pharmaceutical industry. The Benson method, employed to estimate thermodynamic properties of the compounds involved in the reaction, was considered adequate for this system, since it gave an isomer distribution resembling other similar aromatic compounds.

The results indicate that, although the $\mathrm{O}$-acylation is kinetically favored, hydroxyacetophenones (C-acylation) are yielded as almost single products from the reaction between acetic acid and phenol at temperatures between $300 \mathrm{~K}$ and $800 \mathrm{~K}$. At higher temperatures, however, the formation of about $20 \%$ of phenyl acetate (O-acylation) takes place.

Similarly to other disubstituted aromatic compounds, meta-HAP is the most stable out of the three isomers. Ortho-HAP is the least stable isomer, resembling the diethylbenzenes (DEB) in behavior. This could indicate that the formation of the ortho-isomer of disubstituted benzenic compounds is influenced by the size $(\mathrm{OH}$ and $\mathrm{COCH}_{3}$ in the case of HAP and $\mathrm{C}_{2} \mathrm{H}_{5}$ in the case of DEB) but apparently not by the electronic properties of the substitutes present in the aromatic ring.

\section{Acknowledgments}

We acknowledge the financial support given by CAPES for the realization of this work.

\section{References}

1. Hölderich, W.F.; Bekkum, H. van. In Introduction to Zeolite Science and Practice, Bekkum, H. van et al. Eds., Stud. Surf. Sc. Catal. 1991, 58, 631.

2. Bekkum, H. van; Hoefnagel, A.J.; Koten, M.A. van; Gunnewegh, E.A.; Vogt, A.H.G.; Kouvenhoven, H.W. In Zeolites and Micropore Crystals, Hattori, T.; Yashima, T. Eds., Stud. Surf. Sc. Catal. 1993, 83, 379.

3. Neves, M.I.P.C. Alkylation et acylation du phenol sur zéolithes Y et ZSM-5. Formation de coke et desactivation, PhD Dissertation, Université de Poitiers 1993.

4. Pouilloux, Y.; Gnep, N.S.; Magnoux, P.; Perot, G. J. Mol. Catal. 1987, 40, 231.

5. Neves, I.; Jayat, F.; Magnoux, P.; Pérot, G.; Ribeiro, F.R.; Gubelmann, M.; Guisnet, M. J. Mol. Catal. 1994, 93, 169.

6. Sobrinho, E.V.; Cardoso, D.; Souza-Aguiar, E.F.; Jayat, F. $9^{\circ}$ Congresso Brasileiro de Catálise, 1997.

7. Guisnet, N.; Lukyanov, D.B.; Jayat, F.; Magnoux, P.; Neves, I. Ind. Eng. Chem. Res. 1995, 34, 1624.

8. Ried, R.C.; Prausnitz, J.M.; Sherwood, T.K. In The properties of gases and liquids, McGraw-Hill, New York 1988.

9. Benson, S.W.; Cruickshank, F.R.; Golden, D.M.; Haugen, G.R.; O’Neall, H.E. Chemical Review 1969, 69, 279

10. Stull, D.R.; Westrum, E.F.; Sinke, G.C. In The Chemical Thermodynamics of Organic Compounds, J. Wiley, New York 1969.

11. Kaeding, W.W. J. Catal. 1981, 67, 159.

12. Barzón, A.A. In Formação do etilbenzeno sobre a zeólita ZSM-5 por desproporcionamento do etilbenzeno, MSc. Dissertation, Universidade Federal de São Carlos, Brazil 1990.

FAPESP helped in meeting the publication costs of this article 